\title{
High Performance n-MOSFETs with Novel Source/Drain on Selectively Grown Ge on Si for Monolithic Integration
}

Hyun-Yong $\mathrm{Yu}^{1}$, Masaharu Kobayashi ${ }^{1}$, Woo Shik Jung ${ }^{1}$, Ali K. Okyay ${ }^{2}$, Yoshio Nishi ${ }^{1}$, Krishna C. Saraswat ${ }^{1}$

${ }^{1}$ Department of Electrical Engineering, Stanford University, CIS, Stanford, CA, 94305, USA

${ }^{2}$ Department of Electrical and Electronics Engineering, Bilkent University, Ankara, Turkey 06800

(Phone) +1-650-799-6735, (FAX)+1-650-723-4659, (E-mail) yuhykr@stanford.edu

\begin{abstract}
s
We demonstrate high performance Ge n-MOSFETs with novel raised source/drain fabricated on high quality single crystal Ge selectively grown heteroepitaxially on Si using Multiple Hydrogen Anealing for Heteroepitaxy(MHAH) technique. Until now low source/drain series resistance in Ge n-MOSFETs has been a highly challenging problem. Source and drain are formed by implant-free, in-situ doping process for the purpose of very low series resistance and abrupt and shallow $n^{+} / p$ junctions. The novel n-MOSFETs show among the highest electron mobility reported on (100) Ge to-date. Furthermore, these devices provide an excellent $\mathrm{I}_{\text {on }} / \mathrm{I}_{\text {off }}$ ratio $\left(4 \times 10^{3}\right)$ with very high $I_{\text {on }}$ of $3.23 \mu \mathrm{A} / \mu \mathrm{m}$. These results show promise towards monolithic integration of Ge MOSFETs with $\mathrm{Si}$ CMOS VLSI platform.
\end{abstract}

\section{Introduction}

As Si bulk CMOS devices approach their fundamental scaling limit, diverse research is being done to introduce novel structures and high mobility channel materials to circumvent this limit. The lower effective mass in Ge that leads to higher mobility of carriers compared to Si has prompted renewed interest in Ge-based devices. Moreover, monolithic integration of Ge with Si devices could provide an alternative solution for continued scaling of devices for future nanoelectronics applications. Very promising results for bulk Ge p-MOSFETs have been demonstrated, with up to $4 \times$ hole mobility enhancement. However, Ge n-channel MOSFETs have exhibited very poor performance that obstructs CMOS device realization in Ge. The poor passivation of $\mathrm{Ge}$ interface is one of the critical challenges. Also, relatively low n-type dopant solubility $[1,2]$ and fast n-type dopant diffusion [3] during dopant activation in $\mathrm{Ge}$ make it difficult to fabricate source and drain (S/D) in nchannel Ge MOSFETs. This paper provides a promising approach for high performance Ge MOSFET processing techniques, in particular Ge growth with in-situ doping for raised source/drain and monolithic integration of Ge with Si CMOS VLSI platform.

\section{Selective Ge heteroepitaxial growth}

The initially deposited rough Ge surface due to the lattice mismatch with $\mathrm{Si}$, characterized by islanding is considerably smoothened by a high temperature hydrogen annealing [4]. On this smooth layer, second epitaxial growth is performed, followed by another hydrogen annealing until desired epi layer thickness is reached. This MHAH procedure is performed on selectively grown $\mathrm{Ge}$ on $\mathrm{Si}$ through a $\mathrm{SiO}_{2}$ window for monolithic integration (Fig 1). Under low deposition temperature $\left(600^{\circ} \mathrm{C}\right)$ and partial pressure (8Pa), excellent selectivity is obtained, with Ge deposited only on the exposed Si surface and not on the oxide region. However, when either the temperature or pressure is increased, Ge can nucleate more easily on $\mathrm{SiO}_{2}$ surface, and selectivity tends to be degraded. The reduction in the Ge nucleation density comes at the expense of lower Ge growth rate, thus a compromise may be needed when choosing the growth condition for selective Ge growth. After 4 cycles of deposition and hydrogen annealing on the selective area $(50 \mu \mathrm{m} \times 50 \mu \mathrm{m})$, the root mean square (RMS) roughness of the resulting film was determined to be $0.65 \mathrm{~nm}$ by atomic force microsco microscopy (AFM) scans on $10 \mu \mathrm{m} \times 10 \mu \mathrm{m}$ area (Fig. 2, 3). Due to the multi-step Ge growth, $\mathrm{H}_{2}$ annealing, and dislocation trapping by $\mathrm{SiO}_{2}$ sidewall on the selective area, high quality Ge film with minimal dislocation density $\left(<10^{7} \mathrm{~cm}^{-2}\right)$ can be achieved at the smaller window size (Fig. 4). The undoped epitaxial Ge layer shows a slightly p-type $\left(5 \times 10^{14} \mathrm{~cm}^{-3}\right)$ characteristic.

\section{Ge $n^{+} / p$ junction diode characteristics}

For an abrupt and box shape $n^{+} / p$ junction in Ge, insitu doping with phosphorus (P) using $\mathrm{PH}_{3}$ is applied during the epitaxial growth. A four-point probe method was used to measure the sheet resistance of n-type in-situ doped Ge layers. The resistivity of this P-doped Ge layer decreases monotonously with increase in $\mathrm{F}\left(\mathrm{PH}_{3}\right) / \mathrm{F}\left(\mathrm{GeH}_{4}\right)$ mass-flow ratio until it reaches a minimum value and eventually increases due to the formation of polycrystalline Ge (Fig. 6). The growth rate is relatively independent of the mass-flow ratio, and mainly depends 
on the growth temperature. Measured growth rates are 65 , 53.5 , and $43 \mathrm{~nm} / \mathrm{min}$ at the growth temperature of 600,500 , and $400^{\circ} \mathrm{C}$, respectively. At $600^{\circ} \mathrm{C}$ growth temperature, the resulting $n^{+} / p$ junction has a junction depth of $97 \mathrm{~nm}$ and a peak electrically activated concentration of $2 \times 10^{19} \mathrm{~cm}^{-3}$ (Fig. 7(a)). Larger junction depth (122nm) was obtained in the ion implanted sample annealed at $600^{\circ} \mathrm{C}$ for $1 \mathrm{~min}$. Table 1 compares the results of both techniques. The insitu doped profile also exhibits an abrupt edge near $n^{+} / p$ junction indicated by spreading resistance probe (SRP) data yielding a decay slope of the $\mathrm{P}$ concentration of $13 \mathrm{~nm} /$ decade, while $24 \mathrm{~nm} /$ decade was measured from the ion implanted sample (Fig 7 (a), (d)). The $n^{+} / p$ junction formed by in-situ doping at $600^{\circ} \mathrm{C}$ shows better diode characteristics with $1.1 \times 10^{4}$ on/off ratio and high forward current density $\left(120 \mathrm{~A} / \mathrm{cm}^{2}\right.$ at $\left.1 \mathrm{~V}\right)$ than conventional ionimplanted junction which has $1.37 \times 10^{3}$ on/off ratio and $15 \mathrm{~A} / \mathrm{cm}^{2}$ forward current density at $1 \mathrm{~V}$ (Fig. 8). This is despite the fact that the in-situ doped sample has slightly lower peak electrically active dopant density $\left(2 \times 10^{19} \mathrm{~cm}^{-3}\right)$ than the ion implanted sample $\left(5 \times 10^{19} \mathrm{~cm}^{-3}\right)$. This result can be attributed to the fact that the in-situ doped diode sample does not suffer from defect formation and transient enhanced diffusion and thus has more uniform box shape profile.

\section{Ge n-MOSFETs}

\section{Device fabrication}

A 500-nm-thick $\mathrm{SiO}_{2}$ film was thermally grown on a lightly doped p-type (100) $\mathrm{Si}$ substrate at $1100{ }^{\circ} \mathrm{C}$. The $\mathrm{SiO}_{2}$ film was then patterned by dry-etching followed by wet-etching to define desired locations for Ge growth. The wafer was cleaned according to the standard $\mathrm{Si}$ wafer cleaning process and immediately loaded into an Applied Materials Centura RP-CVD epitaxial reactor. Selective $\mathrm{MHAH}$ technique was used to grow high quality single crystal Ge on Si for Ge n-MOSFET fabrication (Fig. 9). This technique naturally provides a device isolation structure. Based on the $n^{+} / p$ junction technique mentioned above, optimized S/D engineering techniques were implemented to fabricate raised S/D Ge n-MOSFETs. The interface engineering technique including $\mathrm{GeO}_{2}$ passivation was implemented by plasma radical oxidation after a thin Si layer growth $(1-1.5 \mathrm{~nm})$ on epi-Ge. By oxidizing $\mathrm{Si}$ and then $\mathrm{Ge}$, a $\mathrm{SiO}_{2}(3 \mathrm{~nm})$ and $\mathrm{GeO}_{2}(1 \mathrm{~nm})$ layer were formed as the gate stack [5].

\section{$\underline{\text { Device Characterization }}$}

Because suppressing off current and maximizing $\mathrm{I}_{\mathrm{on}} / \mathrm{I}_{\mathrm{off}}$ ratio are challenging issues concerning Ge nMOSFETs, $\mathrm{I}_{\mathrm{on}} / \mathrm{I}_{\text {off }}$ measurement was performed. The Ge n-MOSFETs with $\mathrm{W} / \mathrm{L}_{\mathrm{G}}$ ratio of $130 \mu \mathrm{m} / 100 \mu \mathrm{m}$ provide one of the highest $\mathrm{I}_{\mathrm{on}} / \mathrm{I}_{\text {off }}$ ratio of $4 \times 10^{3}$ at $1.2 \mathrm{~V}$ drain voltage and show the off current density of $6 \times 10^{-4} \mu \mathrm{A} / \mu \mathrm{m}$. In addition, it exhibits high $I_{\text {on }}$ per width $(3.23 \mu \mathrm{A} / \mu \mathrm{m})$ (Fig.10). Effective mobility versus E-field is extracted from Ge nMOSFET by split-CV measurement. For comparison, the Si universal electron mobility is also shown. The data measured from the device show among the highest electron mobility $\left(\mu_{n}\right)$ reported on (100) Ge to-date with peak $\mu_{\mathrm{n}}$ being around $540 \mathrm{~cm}^{2} / \mathrm{V}$-s (Fig. 12) [6].

\section{Conclusion}

We have successfully achieved high performance Ge n-MOSFETs by using novel raised S/D technology on the selectively grown Ge on $\mathrm{Si}$. Excellent diode and transistor on/off ratios are obtained in Ge n-MOSFET. It also shows the highest electron mobility on (100) Ge to-date. This Ge MOSFET fabrication technique shows a promising step toward integrating high performance Ge devices with $\mathrm{Si}$ CMOS VLSI platform.

\section{Acknowledgement}

This work was supported by FCRP/MARCO Interconnect Focus Center and the Stanford University INMP program and was done in the Stanford Nanofabrication Facility (SNF) which is funded by the NSF NNIN grant.

\section{References}

[1] F. A. Trumbore, Bell Syst. Tech. J. 39, 205 (1960)

[2] B. L. Sharma, Defect Diffus. Forum 70-71, 1 (1990)

[3] W. C. Dunlap, Phys. Rev. 94, 1531 (1954)

[4] Nayfeh et al, Appl. Phys. Lett. 85, 2815.

[5] Masaharu et al., VLSI 2009, p.76.

[6] Kuzum et al., IEDM 2007, p.723.

[7] Park et al., IEDM 2008, p.389.

[8] Takahashi et al., IEDM 2007, p.697. 


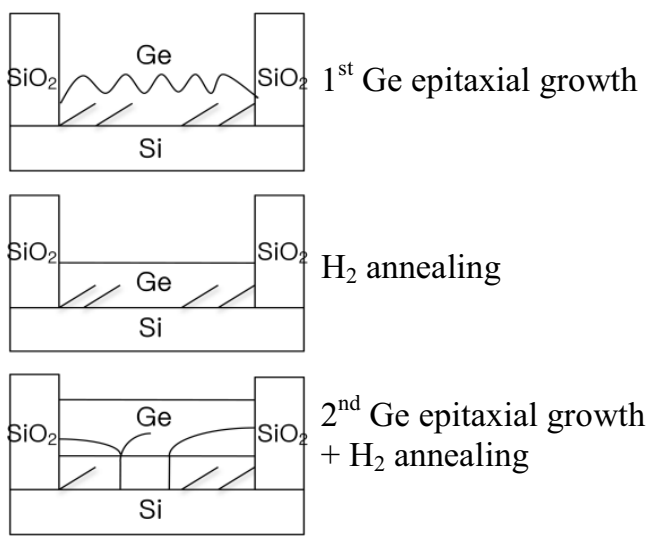

Fig. 1 Process flow schematic of the selective MHAH method to grow high quality Ge layer on $\mathrm{Si}$ for the monolithic integration. Here, hydrogen annealing effectively reduces the surface roughness.

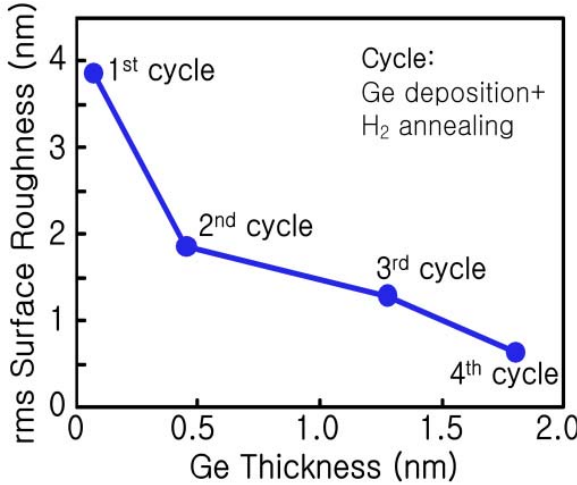

Fig. 2 RMS surface roughness as a function of the thickness of selectively grown Ge on Si. $\left(50 \mu \mathrm{m} \times 50 \mu \mathrm{m} \mathrm{SiO}_{2}\right.$ window size for Ge growth) (a)

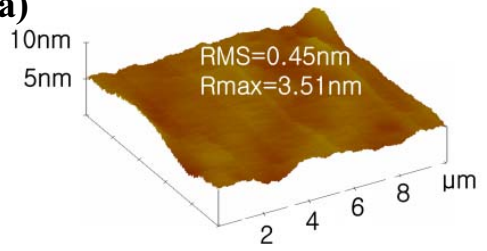

(b)

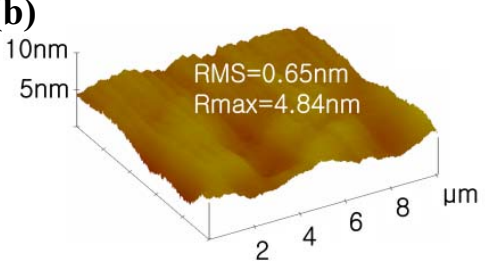

Fig. 3 Tapping mode AFM images of $1.8 \mu \mathrm{m}$ thick (a) bulk Ge growth and (b) selective $\mathrm{Ge}$ growth after MHAH. The RMS surface roughness of (a) and (b) is 0.41 and $0.61 \mathrm{~nm}$ respectively.

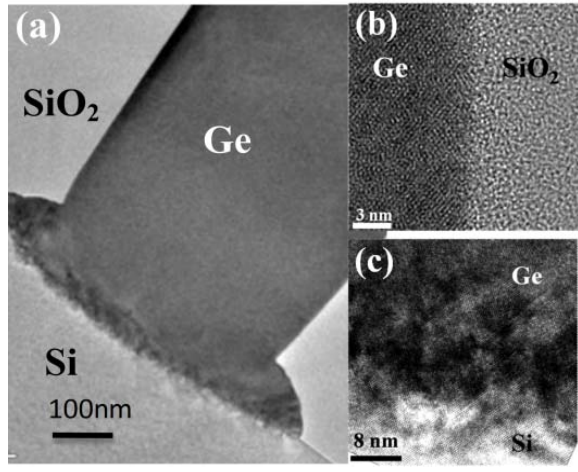

Fig. 4 (a) Cross-sectional TEM image of epi-Ge layer selectively grown on patterned $\mathrm{SiO}_{2} / \mathrm{Si}$ with $500 \mathrm{~nm} \mathrm{SiO}_{2}$ window width. (b) High resolution image at the interface between Ge layer and $\mathrm{SiO}_{2}$ side wall. (c) High resolution image at the interface between Ge layer and $\mathrm{Si}$ substrate.

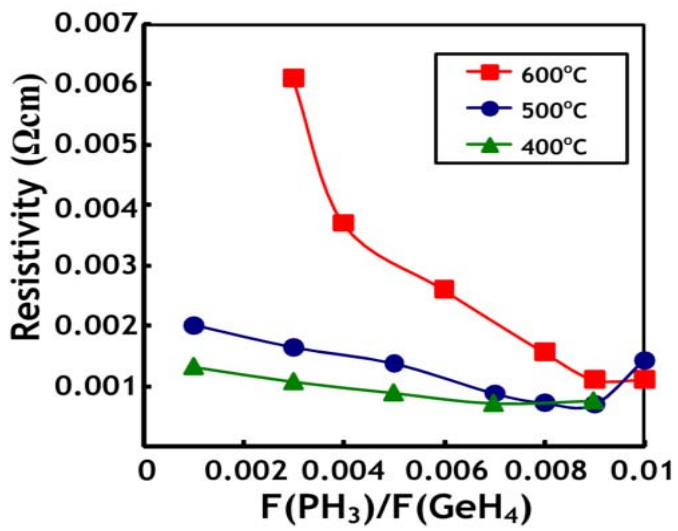

Fig. 6 Resistivity of phosphorus-doped Ge layers as a function of the $\mathrm{F}\left(\mathrm{PH}_{3}\right) / \mathrm{F}\left(\mathrm{GeH}_{4}\right)$ mass-flow ratio after in-situ doped layer growth.

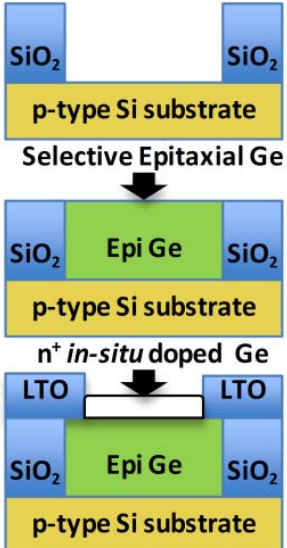

9
0
0
0
1
Open $\mathrm{SiO}_{2}$ window for $\mathrm{Ge}$ growth

Selectively epitaxial Ge growth on patterned $\mathrm{SiO}_{2}$ window

Isolation using LTO

Etch LTO for $\boldsymbol{n}^{+}$Ge layer

Selectively $n^{+}$in-situ doped Ge growth

\section{Electrode deposition ( $\mathrm{Ti} / \mathrm{Al})$}

Measurement
Fig. 5 Schematic images and process flow for $n^{+} / p$ junction formation on selectively grown $\mathrm{Ge}$ (undoped epitaxial growth Ge; p-type substrate : $5 \times 10^{14} \mathrm{~cm}^{-}$ ${ }^{3}$ ) using in-situ doped growth method.
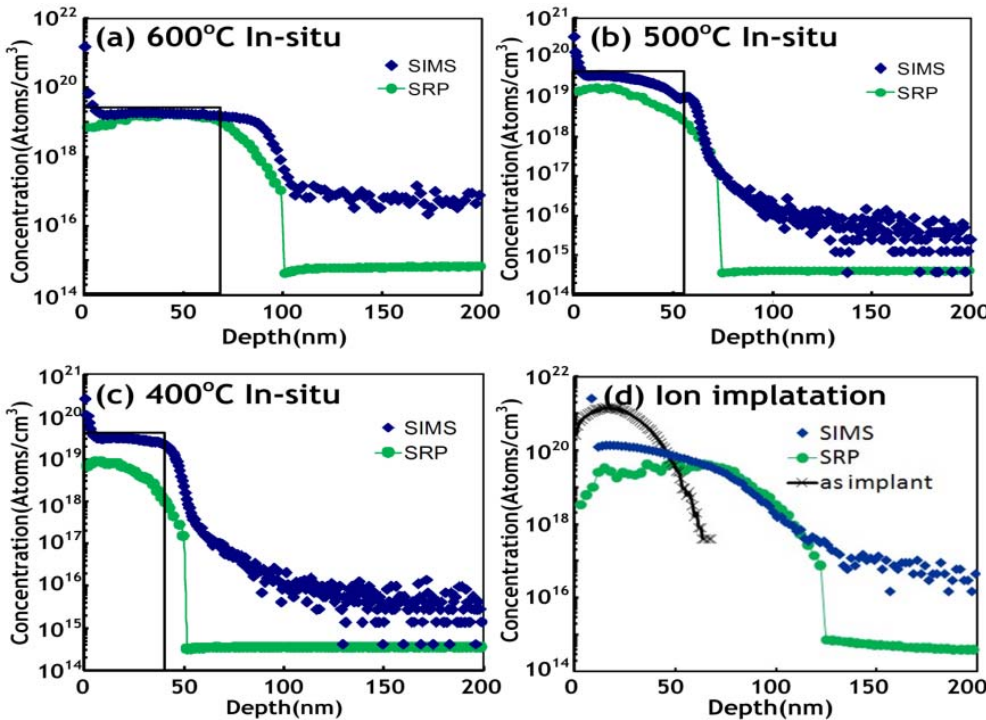

Fig. 7 SIMS and SRP profiles (carrier concentration $\left(\mathrm{cm}^{-3}\right)$ as functions of depth (nm)) in $n^{+} / p$ junction using (a) $600^{\circ} \mathrm{C}$, (b) $500^{\circ} \mathrm{C}$, and (c) $400^{\circ} \mathrm{C}$ in-situ doped Ge layer growth for $1 \mathrm{~min}$, and (d) ion implanted $\mathrm{Ge}$ annealed at $600^{\circ} \mathrm{C}$ for $1 \mathrm{~min}$.

$\mathrm{P}_{31}+: 4 \times 10^{15} \mathrm{~cm}^{-2}$ and $18 \mathrm{keV}$ 


\begin{tabular}{|c|c|c|c|}
\hline & $\begin{array}{c}\text { Abruptness } \\
(\mathrm{nm} / \text { decade) }\end{array}$ & $\begin{array}{c}\text { Junction } \\
\text { depth(nm) }\end{array}$ & $\begin{array}{c}\text { Activation } \\
(\%)\end{array}$ \\
\hline $\begin{array}{c}\mathbf{6 0 0}^{\circ} \mathrm{C} \\
\text { in-situ }\end{array}$ & 13 & 100 & 100 \\
\hline $\begin{array}{c}500^{\circ} \mathrm{C} \\
\text { in-situ }\end{array}$ & 8 & 75 & 65 \\
\hline $\begin{array}{c}400^{\circ} \mathrm{C} \\
\text { in-situ }\end{array}$ & 7 & 64 & 30 \\
\hline $\begin{array}{c}\text { Ion } \\
\text { Implantation }\end{array}$ & 24 & 122 & 50 \\
\hline
\end{tabular}

Table. 1 Comparison of Ge $n^{+} / p$ junctions for different in-situ doped Ge conditions and ion implantation with $600^{\circ} \mathrm{C} / 1 \mathrm{~min}$ annealing.

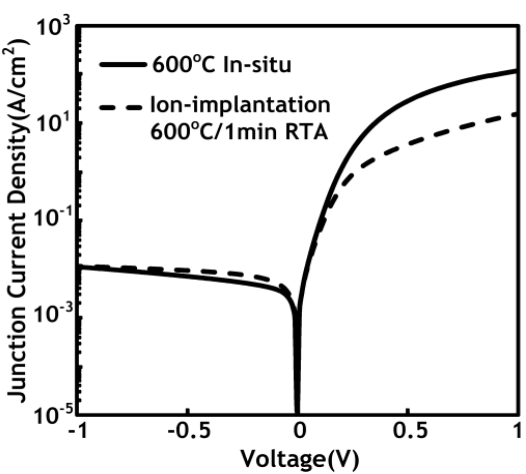

Fig. $8 n^{+} / p$ junction current density $\left(\mathrm{A} / \mathrm{cm}^{2}\right)$ of $600^{\circ} \mathrm{C}$ in-situ doped and ion implantation samples.
Thermal oxidation, etch oxide window

Selectively epitaxial Ge growth on patterned $\mathrm{SiO}_{2}$ window

LTO deposition, etch LTO for S/D

Selectively $n^{+}$in-situ doped Ge

growth on S/D (a)

Etch LTO on Gate

Si epitaxial growth and plasma radical oxidation $\left(\mathrm{SiO}_{2} / \mathrm{GeO}_{2}\right)(\mathrm{b}, \mathrm{c})$ Al deposition and pattern Gate $\operatorname{stack}\left(\mathrm{Al} / \mathrm{SiO}_{2} / \mathbf{G e O}_{2}\right)$ Forming gas annealing $@ 350^{\circ} \mathrm{C}(\mathrm{d})$ (a)

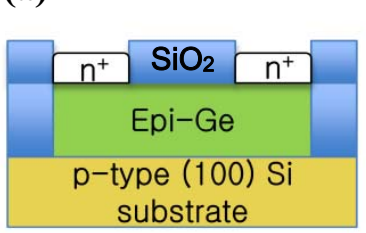

(c)

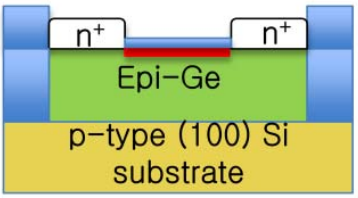

Plasma radical

(b) oxidation

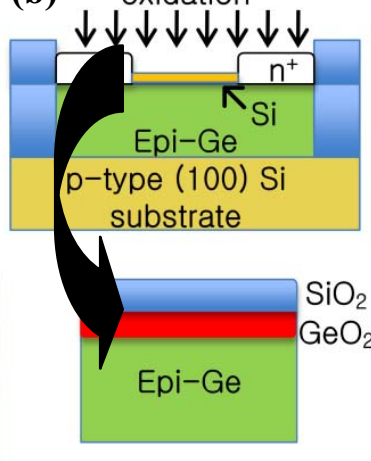

(d)

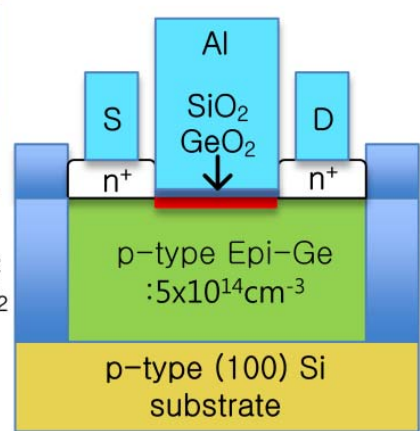

Fig. 9 Ge n-MOSFETs process flow. Selectively grown epitaxial Ge (p-type: $5 \times 10^{14} \mathrm{~cm}^{-3}$ ) is used for n-MOSFETs. (a) Based on the selectivity, the $n^{+}$in-situ doped $\mathrm{Ge}\left(600^{\circ} \mathrm{C}, 1 \mathrm{~min}\right)$ is formed at $\mathrm{S} / \mathrm{D}$, defined by $\mathrm{SiO}_{2}$ window. (b) After a thin layer $\mathrm{Si}$ growth on epi-Ge, $\mathrm{Si}$ and $\mathrm{Ge}$ are oxidized by plasma radical oxidation step, forming $\mathrm{SiO}_{2}(3 \mathrm{~nm})$ and $\mathrm{GeO}_{2}(1 \mathrm{~nm})$ as gate stack.

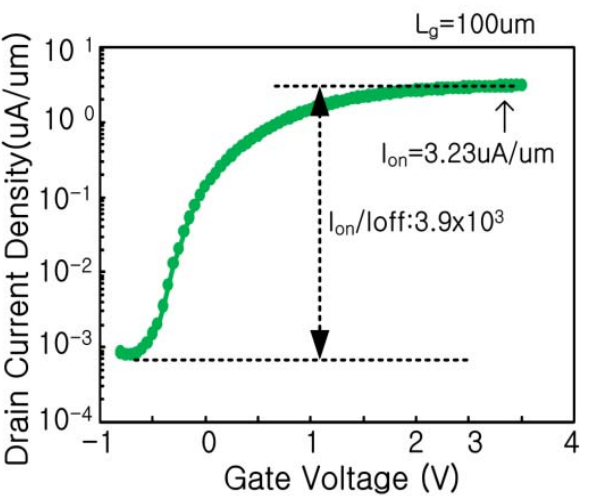

Fig. $10 \mathrm{I}_{\mathrm{D}}(\mu \mathrm{A} / \mu \mathrm{m})-\mathrm{V}_{\mathrm{G}}(\mathrm{V})$ characteristics for Ge n-MOSFET fabricated on undoped epi-Ge. $\mathrm{I}_{\text {on }} / \mathrm{I}_{\text {off }}$ is $3.9 \times 10^{3}$ when $\mathrm{V}_{\mathrm{D}}$ is $1.2 \mathrm{~V}$. $\mathrm{I}_{\text {on }}$ is $3.23 \mu \mathrm{A} / \mu \mathrm{m}$.

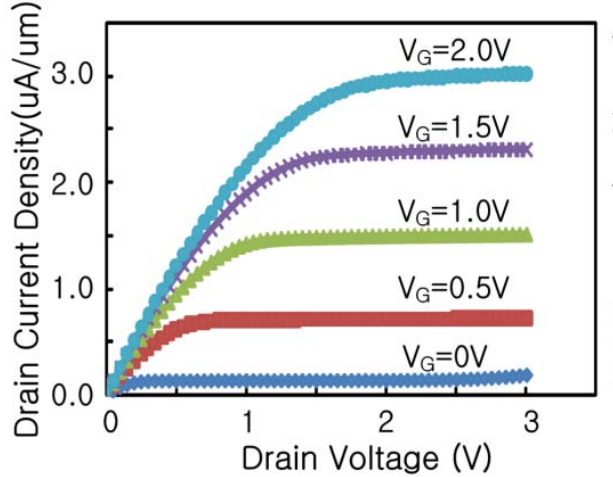

Fig. $11 I_{D}(\mu A / \mu m)-V_{D}(V)$ characteristics for Ge n-MOSFET $\left(\mathrm{L}_{\mathrm{G}}=100 \mu \mathrm{m}\right)$ fabricated on selective undoped epi-Ge on Si (p-type: $\left.5 \times 10^{14} \mathrm{~cm}^{-3}\right)$.

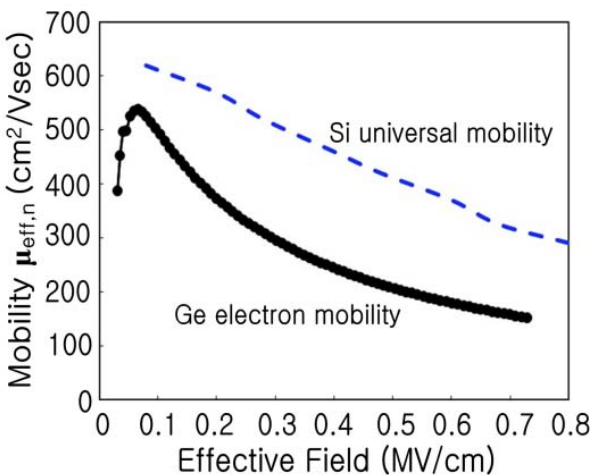

Fig. 12 Electron mobility $\left(\mathrm{cm}^{2} / \mathrm{V} \cdot \mathrm{sec}\right)$ as a function of effective field $(\mathrm{MV} / \mathrm{cm})$ in Ge n-MOSFET on selectively grown epitaxial Ge (p-type: $5 \times 10^{14} \mathrm{~cm}^{-3}$ ).

\begin{tabular}{|c|c|c|c|}
\hline & $\begin{array}{c}\text { Diode } \\
\text { on/off }\end{array}$ & $\begin{array}{c}\text { Transistor } \\
\text { on/off }\end{array}$ & $\begin{array}{c}\text { Peak } \mu_{\mathrm{n}} \\
\left(\mathrm{cm}^{2} / \mathrm{Vs}\right)\end{array}$ \\
\hline This work & $10^{4}$ & $4 \times 10^{3}$ & 540 \\
\hline Ref. [6] & $10^{3}$ & $10^{1.5}$ & 420 \\
\hline Ref. [7] & $10^{4}$ & $1 \times 10^{3}$ & 410 \\
\hline Ref. [8] & $10^{3}$ & - & 270 \\
\hline
\end{tabular}

Table. 2 Comparison of $\mathrm{Ge}$ nMOSFETs performance in this work and previously reported data. 